\title{
LA "ÉTICA DIALÓGICA" LATINOAMERICANA: APORTES DE ENRIQUE DUSSEL Y RAUUL FORNET BETANCOURT
}

\author{
Prof. Dr. José Alfredo Moncada Sánchez ${ }^{1}$ \\ Universidad Nacional Experimental del Táchira, Venezuela
}

\begin{abstract}
Resumen: La "ética dialógica" latinoamericana es una alternativa de reflexión de la posición de la "comunidad de las víctimas" ante la colonialidad del ser y del saber. De aquí surge la necesidad de entablar puentes con las otras maneras de comprender e interpretar los contextos culturales propios. Este trabajo tiene como finalidad el reflexionar sobre la perspectiva de pensadores como Leopoldo Zea y José Gaos para justificar la necesidad de una ética latinoamericana. Y, de Enrique Dussel y Raúl Fornet-Betancourt hacia la consolidación de una ética donde el "Otro", en el reconocimiento de su "otredad", pueda dialogar críticamente con los procesos "civilizatorios" instalados en la modernidad y entablar caminos de entendimiento entre ambos. Categorías a considerar para este entendimiento están el principio de la "vida del sujeto", la palabra, la acción, la narración, "comunidad de víctimas", la acción comunicativa, el encuentro, entre otros.
\end{abstract}

Descriptores: El Otro $\cdot$ La comunidad de víctima $\cdot$ El encuentro $\cdot$ La palabra $\cdot$ El diálogo.

Abstract: Latin American "dialogic ethics" is an alternative to reflect the position of the "community of victims" in the face of coloniality of being and knowledge. Hence the need to build bridges with the other ways of understanding and interpreting their own cultural contexts. The purpose of this work is to reflect on the perspective of thinkers like Leopoldo Zea and José Gaos to justify the need for a Latin American ethic. And, by Enrique Dussel and Raúl FornetBetancourt towards the consolidation of an ethic where the "Other", in recognition of his "otherness", can critically dialogue with the "civilizational" processes installed in modernity and establish paths of understanding between both of them. Categories to consider for this understanding are the principle of the "life of the subject", the word, the action, the narrative, "community of victims", the communicative action, the encounter, among others.

Keywords: The Other - The victim community · The encounter · The word · The dialogue

Enviado: 29/05/2019. Aceptado: 25/09/2019.

\section{INTRODUCCIÓN}

La discusión del pensamiento latinoamericano en el ámbito académico es una reflexión permanente para la construcción de las ideas desde nuestro contexto regional. En este sentido, la ética no escapa de esta reflexión de las ideas, precisamente

\footnotetext{
${ }^{1}$ Doctor en Ciencias de la Educación por la Universidad Latinoamericana y del Caribe. Docente e Investigador del Departamento de Ciencias Sociales de la Universidad Nacional Experimental del Táchira. E-mail: jmoncada22771@gmail.com
} 
por ser producto del pensamiento del hombre, de aquí el planteamiento de estudiar una "ética dialógica" latinoamericana que supere la colonialidad del ser y del saber, para crear espacios de enriquecimiento a los conocimientos universales establecidos culturalmente a través del tiempo.

A partir del estudio de diversas fuentes filosóficas emergentes del pensamiento latinoamericano contemporáneo, tales como las contribuciones de Leopoldo Zea, José Gaos, Enrique Dussel, y Raúl Fornet-Betancourt, sistematizan coordenadas teóricas de lo que podría denominarse como una "ética dialógica" latinoamericana. Tal análisis se estructura, sobre todo, a partir de las críticas que desde ella se realizan a la colonialidad tanto del saber, como del ser, en tanto que es producto de la modernidad.

En función de lo precedente, en una primera sección del estudio se reflexiona sobre la perspectiva filosófica de Leopoldo Zea y José Gaos para justificar una ética latinoamericana. Para posteriormente, en la segunda sección, explicar la formación de la ética desde la filosofía de la liberación propuesta por Enrique Dussel, considerando algunas de sus categorías que podrían orientar el estudio, donde el "Otro" como oprimido, explotado o colonizado es la figura principal en la formación de un pensamiento ético y se posiciona como el "sujeto moral" privilegiado. Luego, encontramos a Raúl Fornet-Betancourt con la propuesta de una filosofía intercultural dialógica, como diálogo crítico con el pensamiento etnocéntrico. Y, finalmente confluir ambos posturas filosóficas en la configuración de los lineamientos de una denominada "ética dialógica" latinoamericana.

\section{JUSTIFICACIÓN DE UNA ÉTICA LATINOAMERICANA}

La ética es una acción de la humanidad en función de un conjunto de normas y principios que se establecen en la sociedad para regir la conducta y los actos de sus miembros (Martín, 2009). Partiendo de esta aproximación conceptual de ética donde se establece claramente el fenómeno de reflexión, es importante establecer los lineamientos desde Latinoamérica. De este modo, si la filosofía latinoamericana es un problema del sujeto latinoamericano, la ética también lo es. Uno de los exponentes de tal acción reflexiva es Leopoldo Zea. ${ }^{2}$ En su obra $L a$ filosofia americana como filosofía sin más, ${ }^{3}$ expone que el instrumento que sitúa al hombre en el mundo es la palabra. Con la palabra, el hombre como ente deja de serlo

\footnotetext{
${ }^{2}$ Leopoldo Zea (1912 - 2004), filósofo mexicano, defensor del pensamiento de las ideas latinoamericanas.

${ }^{3}$ En la obra expone su visión opositora al estereotipo de filosofía que exige una correspondencia con los sistemas de corte europeo, por tanto, entiende que reflexionar sobre la realidad latinoamericana es una forma de filosofar, ya que existen varias formas de realizarla. Así como la occidental se inició con poemas, por ejemplo los de Parménides; la americana también puede partir de las obras poéticas, ensayistas, obras teatrales o novelas que están configuradas de ideas contextuales que realzan el pensamiento filosófico latinoamericano.
} 
para convertirse en habitante de un contexto específico, en un hombre situado. Al respecto, dice Zea (2010), p. 9: "los entes dejan de serlo para transformarse en esto o aquello en relación con el hombre que les da esa especial existencia al expresarlo, al hablar de ellos". Es decir, la palabra da existencia al sujeto al expresar la acción de él, argumento respaldado por Bárcena y Mélich (2000), p. 68, quienes señalan: "la acción... [está] en estrecha relación con el discurso, con el poder de la palabra y del lenguaje, es la forma a través de la cual nos insertamos en el mundo, y esa inserción es como un segundo nacimiento cuyo impulso es el comienzo...". Igualmente, Arendt (2009), p. 203, afirma: "Mediante la acción y el discurso, los hombres muestran quiénes son, revelan activamente su única y personal identidad y hacen su aparición en el mundo humano". Por consiguiente, el sujeto latinoamericano por la palabra se sitúa en la universalización del pensamiento, en la historia de la humanidad, como protagonista de los hechos históricos y no como sujetos pasivos de la acción histórica. Ante esta argumentación de posicionarse en el discurso universal con sus ideas surge la necesidad del diálogo ante la cultura etnocéntrica.

Esto ha conllevado como problema del sujeto latinoamericano a preguntarse sobre la existencia o no de un pensamiento autóctono, extendible por supuesto a la ética. Así, Zea (2010), p. 10, manifiesta: “¿De dónde nos viene esa extraña preocupación?". Entonces, reflexiona partiendo de encontrar la génesis de este cuestionamiento, ¿qué es lo que nos diferencia de los otros contextos geográfícos, históricos y culturales para no preguntarnos sobre nuestros pensamientos? Ante la situación, reseña: “a ningún griego se le ocurrió preguntarse por una filosofía griega" (ídem). Simplemente, ellos "pensaban, creaban, ordenaban, separaban, situaban, definían" (op.cit., p. 11). Entonces, ellos simplemente filosofaban. Cabe preguntarse ¿por qué entonces en Latinoamérica se dice que no existe una filosofía? ¿Por qué se dice que la razón de su existencia o no, depende de una sistematicidad? Eso, precisamente se da por la invisibilización del pensamiento, porque si no se fundamenta su pensar a los modelos o arquetipos que se emanan del etnocentrismo, lo que estaría fuera de ello carecería de credibilidad o de validez epistemológica. Por eso, "tal es el caso de quienes en América Latina, desde algún tiempo, y en otros lugares al margen del mundo llamado occidental, se preguntan por la posibilidad de una filosofía" (op.cit., p.10).

Atendiendo a estas consideraciones previas, el primer problema reflexionado en el contexto del filosofar latinoamericano, es un problema sobre el hombre, es decir, un problema ético. Este problema refiere sobre la invisibilidad del mismo, ejecutado desde la historia etnocéntrica. Afirma Mignolo (2005, p. 16): "Los autores reconocen que hay un mundo y unos pueblos fuera de Europa, pero también es cierto que ven a esos pueblos y a los continentes en que habitan como 'objetos', no como sujetos, y en cierta medida los dejan fuera de la historia”. Por consiguiente, 
al no reconocerse su existencia como sujeto de igualdad en condiciones humanas, estamos ante una disyuntiva ética de reconocimiento del "otro", como sujeto histórico. Afirmando lo señalado, tenemos que:

La historia es un privilegio de la modernidad europea, y para tener una historia hay que dejarse colonizar, es decir, dejarse dominar, voluntariamente o no, por una perspectiva de la historia, la vida, el conocimiento, la economía, la subjetividad, la familia o la religión moldeada por la historia de la Europa moderna, que ha sido adoptada como modelo oficial. (ídem).

Entonces, estamos ante una colonialidad del saber y del ser. Por tanto, ante el hecho histórico del "descubrimiento de América", el cual puede ser considerado como "punto de partida" de la modernidad, comenzó a plantearse la negación o no de la humanidad de los habitantes originarios de esta parte del planeta Tierra. Dilema que se discute en el debate histórico de Valladolid, entre Juan Ginés de Sepúlveda ${ }^{4}$ y Bartolomé de las Casas $^{5}$, realizado en los años 1550-1551 y refiere a la valoración que recibieron los pueblos indígenas a partir del "descubrimiento".

Sepúlveda justificaba la explotación de los indígenas del Nuevo Mundo, partiendo del hecho de que carecían de la fe cristiana, por tanto, eran considerados esclavos por naturaleza y subyugados por su conversión a la religión conquistadora. Los argumentos que sirvieron de fuente para su posición fue el concepto de servidumbre natural, encontrada en la obra La Política de Aristóteles (384 a.C.-322 a. C.). Además, en dos conceptos propuesto por Gonzalo Fernández de Oviedo, ${ }^{6}$ como la misión civilizadora de España y la caracterización de los indígenas americanos. Con respecto al segundo concepto: "afirmaba que esta gente era holgazana y corrupta por naturaleza, no les gustaba el trabajo, eran melancólicos y cobardes. No poseían capacidad de recordar o perseverar. Del tamaño de su cabeza era su inteligencia" (Contreras Natera, 2014, p. 56). Estos datos expuesto por Oviedo en su obra Historia general y Natural de las Indias (1535), son los datos empíricos

\footnotetext{
${ }^{4}$ Juan Ginés de Sepúlveda (1490-1573). Es uno de los principales exponentes del humanismo del siglo XVI. Entre sus propuestas teóricas defiende cuatro posiciones que justifican la conquista: El derecho a la tutela que implica la servidumbre y la esclavitud natural de los indígenas. La necesidad de impedir el canibalismo y cualquier forma antinatural. La obligación de salvar a futuras víctimas de dioses falsos y el mandato evangelizador que Cristo le otorgó al Papa y al Rey Católico (Contreras Natera, 2014, p. 52).

${ }^{5}$ Bartolomé de Las Casas (1474 o 1484-1566). Se dedicó a denunciar las injusticias del sistema de encomienda. Entre sus logros iniciales se encuentra la bula Sublimis Deu, emitida en 1573 por el papa Paulo III, que ordenaba a que los indígenas no fueran esclavizados y que fueran evangelizados por medios pacíficos (op.cit.).

${ }^{6}$ Gonzalo Fernández de Oviedo (1478 - 1557). Historiador y cronista de las Indias. Su obra más famosa Historia general y natural de las Indias, en la que se describe el descubrimiento y colonización de las indias americanas. (Disponible en: https://www.biografiasyvidas.com/biografia/f/fernandez_oviedo.htm)
} 
que necesitó Sepúlveda para argumentar sus proposiciones sobre la condición no humana de los pueblos originarios.

Refutando tales afirmaciones, de Las Casas propone como argumento la igualdad que pregona la enseñanza cristiana: "afirmaba que la libertad cristiana corresponde a todos los pueblos del mundo en el mismo grado y los acoge de la misma manera, y no despoja a nadie de su libertad" (ídem. p. 59). Entonces, la discusión ética sostenida en el debate de Valladolid se inclinó a favor de la defensa de Bartolomé de Las Casas. Ahora bien, el desenlace no significó realmente un acto de justicia e igualdad, porque la evangelización llevada a cabo en tierras americanas fue la negación del "otro" desde un plano diferente, como por ejemplo, de las creencias, de las lenguas, de los saberes, de las cosmovisiones, fueron anonadadas por la verdad revelada. Esta invisibilización es una desigualdad cultural entre el etnocentrismo y los pueblos originarios.

Por consiguiente, se está ante un problema ético. A partir de esta problemática "argumentarán, contestarán, tratando de mostrar su propia humanidad. Y son estas argumentaciones las que inician y continúan lo que hemos llamado nuestro extraño filosofar" (Zea, 2010, p. 13).

¿Cuál fue la forma de reaccionar del latinoamericano a tal pretensión?

El latinoamericano (...) tratando de justificar su pretensión de ser hombre (...) se empeñará en someterse al modelo de esta supuesta única firma de lo humano, recortando, destruyendo, lo que sobrase en la calca (...). Recortando lo propio, añadiendo, pero sin asimilar lo extraño, arrancando raíces y levantando utopías. (Íbid., p.17)

Partiendo del hecho de la ética como normas y principios para regir las conductas de los sujetos en sus entornos sociales, en su concepción más simple, las líneas expuestas representa la actitud ética, es decir, la forma como el sujeto latinoamericano responde ante las desigualdades del saber y del ser impuestas desde el modernismo y etnocentrismo. A raíz de esta actitud, surgen dos movimientos, el conservadurismo y el liberalismo: "un conservadurismo que nada quería saber de una nueva imagen del hombre; y la de un liberalismo que creía no tener nada que ver con un pasado que, de alguna forma, había originado" (op.cit., p. 18). Entonces, es una dialéctica entre las diferentes posiciones que posteriormente motivará la búsqueda de un pensamiento propio.

En el siglo XX, dice Zea: “¿Qué hace del hombre un hombre? Y, por ende ¿del latinoamericano un hombre sin más? La libertad” (op.cit., p. 21). Una libertad creadora, que represente la potencialidad del sujeto latinoamericano de autodeterminarse, "un modo de ser que todos los hombres poseen por el hecho de ser hombres...Un modo de ser propio, un modo de ser que no tiene por qué ser semejante 
al de otros pueblos..." (op.cit., p. 22). Es decir, posicionarnos ante la totalidad, entendiéndose por esta categoría, según Dussel (1996), p. 36:

El mundo es entonces una totalidad instrumental, de sentido. No es una pura suma exterior de entes, sino que es la totalidad de los entes con sentido. No se trata del cosmos como totalidad de cosas reales (2.2.3.1), sino que es la totalidad de entes con sentido. El mundo, podríamos decir, se va desplegando lentamente desde el momento de nuestra concepción.

Por consiguiente, la totalidad es el mundo, "todo mundo es totalidad" (íbid., [2.2.2.2], p. 37), es el horizonte donde el sujeto latinoamericano se mueve, hace vida, como seres propios, auténticos, autóctonos, con una visión propia de reflexionar, comprender e interpretar los acontecimientos cotidianos, esto lo posiciona ante el mundo.

En este mismo orden de idea, José Gaos, ${ }^{7}$ con su filosofía explora una alternativa valedera para el pensamiento latinoamericano, donde la filosofía radica en el sujeto que filosofa; en este sentido, la filosofía latinoamericana problematiza en el sujeto latinoamericano que filosofa. Y lo hace sobre el presente, porque "el presente es la única realidad" (Gaos, 2008, p. 85), que debe construirse con el pasado hacia un futuro. En esta línea se ubica la ética latinoamericana.

El pensamiento para Gaos, son objetos inmanentes a los hombres, que poseen una naturaleza histórica debido al tiempo de existencia porque no son eternos, sino como tratan de problemas circunstanciales están en un lugar y tiempo inmediato que necesitan de una resolución urgente. Cada uno de los períodos históricos de los acontecimientos sucedidos en Latinoamérica está acompañado con pensamientos que se construirían para dar sentido a los hechos.

Así, en el período del "descubrimiento", está marcado por la importación de pensamiento, que posteriormente se transformarán en tradición, porque hizo parte de la cultura que comenzó a renacer en el mismo momento en que los españoles pisaron tierra en el Nuevo Mundo. Entonces, se encuentran ante unos problemas nuevos que originaron un pensamiento en el orden de lo jurídico como el tema sobre la legitimidad de la conquista, de lo antropológico como el tema sobre la naturaleza humana de los pueblos originarios y de lo universal, como la verdadera o falsa novedad de lo que es el Nuevo Mundo.

Gaos (2008), en resumen, expone las principales características que identifica a los pensadores de cada una de las épocas por las que transitó el pensamiento latinoamericano. A los pensadores del siglo XVIII los cataloga como religiosos y hombres de ciencia y de letras que empiezan a dejar de serlo. A los pensadores del

\footnotetext{
${ }^{7}$ José Gaos (1900 - 1969). Filósofo español, nacionalizado mexicano en 1941. Su pensamiento se centra en la filosofía de la filosofía, donde señala que la filosofía radica en la personalidad de quien filosofa.
} 
tránsito del siglo XVIII al XIX, resalta su ímpetu revolucionario; los del tránsito del siglo XIX al XX, los considera profesores de filosofía. Además, de heterodoxos o espiritualistas filosóficos. Y al grupo de conforman los pensadores del siglo XVIII hasta las últimas generaciones: demócratas, liberales y republicanos. Todos estos ideales han contribuido con la formación de la filosofía latinoamericana, por tanto, han contribuido también a esa formación ética, que en el transcurso del tiempo se ha convertido en una propuesta más actual, donde la dialogicidad es una acción relevante para posicionar el pensamiento latinoamericano.

En este sentido, ante el problema de la colonialidad del saber que parte desde la colonialidad del ser como se ha demostrado a través del discurso argumentativo descrito en las líneas precedentes, es un problema de relevancia ética y, de aquí, la posibilidad de configurar una ética dialógica. En tal sentido, para cumplir tal propósito se tomarán algunas coordenadas teóricas propuestas por Enrique Dussel y Raúl Fornet-Betancourt.

\section{Perspectivas Del PENSAMIENTO ÉTICO LIBERAdOR PARA UNA ÉTICA DIALÓGICA}

Enrique Dussel (1934 - ), en la elaboración del pensamiento ético, siempre buscó ir más allá de lo establecido por la cultura etnocéntrica. La lectura que realiza Dussel a Emmanuel Levinas (1906 - 1995) le permite trascender de su formación fenomenológica y ontológica heideggeriana. Es decir, romper esa totalidad del ser que dominaba el pensamiento euroccidental hacia la otredad, que implica "una mirada e interioridad profunda de otro ser humano, la alteridad de quien está fuera de todo sistema" (Díaz Novoa, 2000 - 2001, p. 95). Entonces, partiendo de las líneas de fuga encontradas en los discursos éticos desarrollados hasta el momento de sus estudios, fue generando categorías propias, que le permitieron establecer el constructo teórico que sustenta su pensamiento ético.

Una de las críticas a la construcción/fundamentación de la ética moderna tiene que ver con el principio universal material. ${ }^{8}$ Tal principio se fundamenta en las líneas teóricas éticas de los utilitaristas. Ese principio material es la felicidad, que condiciona radicalmente la posibilidad de reproducción y desarrollo de la vida del sujeto humano. Por eso, Dussel (1998a) establece a la vida del sujeto humano como criterio de verdad, en respuesta por el principio establecido por esta rama del pensamiento, señalando:

\footnotetext{
${ }^{8}$ Quien actúa éticamente ya presupone a priori siempre in actu las exigencias (obligaciones, deberes éticos) de la reproducción y desarrollo autoresponsable de la vida del sujeto humano, como mediaciones con verdad práctica, en una comunidad de vida, desde una "vida buena" cultural e histórica, que se comparte solidariamente teniendo por referencia última toda la humanidad, y con ellos con pretensión de universalidad. (Dussel, 1998, p. 11).
} 
podemos afirmar que el criterio de verdad (la vida del sujeto humano) y el principio material ético de él derivado (“Quien actúa...") es estrictamente universal, vigente en toda acción, de todo sujeto ético, y en vista del bien (la reproducción y el desarrollo de la vida del sujeto humano), en último término, de toda la humanidad (Dussel, 1998a, p. 12).

Dussel, estableciendo este criterio de verdad abre las puertas hacia la consolidación de una ética dialógica, porque es un principio universal por ser elemental a la humanidad, ella existe porque hay vida. Al respecto señala:

El criterio de reproducción y crecimiento de la vida humana interno a cada cultura le permite a todas, en primer lugar, ser autocríticas con respecto a los momentos intrínsecos que impiden dicha vida; $y$, en segundo lugar, les permite desde la universalidad de ese criterio efectuar un diálogo con toda otra cultura (en cuanto a lo válido o inválido de su manera de llevar a cabo la reproducción y desarrollo de la vida humana). (Íbid., p.13).

También es importante resaltar que con la ética de la liberación, Dussel objeta algunas corrientes que fundamentan el proceder ético, como las ontológicas norteamericanas, la del discurso europeo y la propuesta del "más allá de una filosofía de la liberación". En este sentido, partiendo de la objeción del primer caso, de la ética ontológica, manifiesta que siempre en el mundo de la vida hay otro oprimido y negado, y que para esas culturas es una opresión justificada por el Bien, único fin material, como se demostró en el debate de Valladolid expuesto anteriormente. Es así que, en todo contexto socio - cultural no se puede negar la existencia de algún "otro". Por tanto, la ética de la liberación desde esta perspectiva intenta superar esos puntos de referencias difíciles de valorar de los sistemas dados, porque cada uno establece un principio como criterio de verdad, valedero para un contexto específico o constructo teórico. Así que, en atención a lo anteriormente descrito, el punto de partida para la ética de la liberación es el "Otro" oprimido, no el ente universal como en la ética ontológica.

En referencia a la segunda objeción sobre del discurso europeo, especialmente la Ética del Discurso, cuyos principales exponentes son J. Habermas (1929- ) y K-O Apel (1922-2017), Dussel indica que la primera pregunta que los participantes de una comunidad de comunicación hegemónica deben hacerse es: ¿A quiénes hemos dejado por fuera o excluidos de la comunidad? Para respuesta a ello es necesario tener conciencia para reconocer a cada participante, "Otro" distinto a todo el resto. En este reconocimiento del "Otro como otro" es el momento ético originario por dársele el lugar que le corresponde al "Otro", no con una participación de igualdad, sino como un Otro libre, un Otro como otro, un Otro como sujeto de nuevo derecho (Dussel, 1998b). Es decir, sin dejar ser lo que es, o hacerse un igual a los de la comunidad de comunicación, manteniendo su originalidad como sujeto.

Otra de las objeciones de Dussel es a la propuesta de la Filosofía de la Liberación de J. C. Scannone, quien propone, que partiendo de la comunidad 
de comunicación de K-O. Apel, se accede a un "nosotros" del pueblo latinoamericano como sujeto. Entonces el punto de partida desde esta óptica latinoamericana es desde el "estar" o del "nosotros estamos". Scannone lo intuye en la “sabiduría popular". Esto es lo que objeta especialmente Dussel, porque es una extensión ontologista de las corrientes éticas del pensamiento occidental, ese “estar", el "nosotros estamos", es ambiguo. Por tal razón, plantea, si ese saber popular se sitúa como el Otro oprimido pues la dinámica del discurso de esta corriente de pensamiento se transforma y toma sentido.

Entonces, Dussel, no rechaza del todo las propuestas planteadas por los pensadores aquí señalados, sino desde la Ética de la Liberación observa las deficiencias coyunturales que presenta, subsume los planteamientos y le da respuesta desde una praxis liberadora, y como ella permite la comprensión del "otro", que forma parte de la mundo global del cual ha sido invisibilizado.

Partiendo de estas objeciones, el punto de partida de la Ética de la Liberación, entonces, es el "Otro", no como otra personal-igual, sino como sujeto libre, con nuevo derecho (Dussel, 1998b). Por consiguiente, en esta propuesta ética latinoamericana, la "realidad concreta", en su fundamentación material, está más allá de la “comprensión del ser”, más allá de una comunidad de comunicación, más allá de una sabiduría afirmada. Este más allá, se transforma en estos tres momentos de conciencia: la conciencia o el saber que se es "afectado", la de ser un dominado dentro de los sistemas establecidos, y los excluidos, como el pobre que no puede reproducir su vida en todos los contextos (op. cit.).

En referencia a lo descrito, ese Otro que es el oprimido y excluido, la Ética de la liberación no lo presenta como una realidad formal vacía, sino como una realidad plena de sentido, de memoria, de cultura, de una comunidad, un "nosotros-estamos-siendo" como una realidad resistente a los sistemas establecidos.

Entonces, en el pensamiento dusseliano, la razón ética originaria es el momento primero racional, es decir, anterior a todo otro ejercicio que la razón haya de realizar. Esta razón ética originaria establece un "estar-siendo-por-elotro", el reconocimiento del Otro. Este reconocimiento, establece una acción comunicativa en el encuentro con el Otro, que es el "Otro-afectado-excluido" (op.cit.)

La razón ética originaria está en el principio de la liberación del pobre, del dominado, de la víctima, del excluido, del invisibilizado, porque él descubre el rostro encubierto que posee, y se reconoce como persona, como el Otro, como sujeto dentro de un proceso de liberación, con una participación plena de esa nueva comunidad que se ha transformado. A todo este proceso Dussel lo 
denomina como formación de la "comunidad de víctimas"; es el sujeto moral por excelencia de la ética.

\section{Perspectivas intercultural de una ética del diálogo}

La propuesta de Raúl Fornet-Betancourt, que aquí nos ocupa, es la constitución de una nueva figura filosófica que denomina: "filosofía intercultural"; conformada por una "nueva constelación de saberes y culturas" (Fornet-Betancourt, 2001, p.29), donde el diálogo es la acción principal que mueve este pensamiento. Es una nueva figura dentro de la filosofía, primero porque:

(...) será una manera de hacer y practicar la filosofía que brota de lo inédito (...) crear desde las potencialidades filosóficas que se vayan historizando en un punto de convergencia común, es decir, no dominado ni colonizado culturalmente por ninguna tradición cultural. (Ídem).

Esta figura responde a la inquietud que ha rodeado al estudio de la filosofía latinoamericana, sobre la constitución de un pensamiento autóctono, que sólo se dará reconociendo las potencialidades de quien reflexiona su existencia, en este caso, el sujeto latinoamericano. En este sentido, un segundo presupuesto del porque se trata esta nueva figura: “... es un proceso eminentemente polifónico donde se consigue la sintonía y armonía de las diversas voces por el continuo contraste con el otro y el continuo aprender de sus opiniones y experiencias" (ídem).

Pues una figura de habla y escucha diversas donde lo referente al "otro" es lo primordial para el establecimiento de un dialogo de respeto y reconocimiento. Por consiguiente, la tercera explicación partiendo de esta polifonía de fomentar "el hábito de intercambiar y de contrastar" (op. cit., p.30) es que se:

(...) prefiere entrar en el proceso de búsqueda creadora que tiene lugar justo cuando la "interpretación" de lo propio y del otro va brotando como resultado de la interpelación común, mutua, donde la voz de cada uno es percibida al mismo tiempo como un modelo de interpretación también posible. (Ídem).

Se resalta la importancia interpretativa de lo propio con lo otro, donde existe una reflexión sobre el papel que representa cada uno de ellos en la globalidad donde ya no está la supremacía de un pensamiento, sino una comunicación e interpretación simétrica.

Como cuarta novedad: "su visión es más bien sentar la reflexión filosófica en el momento de la interconexión, de la intercomunicación; y abrir paso de esta suerte a la figura de una razón inter-discursiva" (ídem). Lo importante es la comprensión e interpretación de lo propio y lo otro, y para eso es necesario una razón 
otra. He aquí, que "hay que partir de la propia tradición cultural, pero sabiéndola y viviéndola no como instalación absoluta sino como tránsito y puente para la intercomunicación" (op. cit., p. 31). Es decir, la tradición cultural relativa por su constitución contextual es el medio de comunicación entre lo propio y lo otro.

La filosofía intercultural, en quinto lugar, "procura abrir el espacio compartido e interdiscursivo (...) como un proceso histórico de enriquecimiento continuo posibilitado justamente por la dinámica de una constante transculturación de la 'trans-portamos' nuestras tradiciones y dejamos que nos transporten otras, y nos hacemos así agentes pacientes de verdaderos proceso de universalización" (ídem). Es decir, desde esta perspectiva filosófica, lo propio no es visto como dogma o un imperativo categórico, sino es un camino que nos transportan hacía lo propio y hacia los demás, que son elementos constructivos de una universalización de comprensión e interpretación mutua.

De esta manera, la filosofía intercultural, como sexto punto:

Propone buscar la universalidad desligada de la figura de la unidad que, como muestra la historia, resulta fácilmente manipulable por determinadas culturas. Quiere decir que se parte de la sospecha de que hasta hoy no se ha conocido ni, mucho menos, realizada históricamente la universalidad. (Op. cit., p. 31).

Es así que la filosofía intercultural abre el camino a una verdadera universalidad de la historia, donde el pensamiento único sea un pensamiento polifónico donde no haya pensamiento único, donde todas las voces interculturales construya los saberes de una globalidad inclusiva, donde escucha y habla sea lo fundamental en todo proceso de diálogo.

Este diálogo intercultural encuentra en la filosofía latinoamericana su modelo en la filosofía de la liberación, a pesar de sus diferencias internas representa una filosofía propia de la cultura de América Latina: "Se trata... de un modelo de filosofía que habla desde la conciencia explícita de ser una reflexión filosófica que no es prolongación de otra tradición, sino que tiene raíces en su propia tradición cultural" (op. cit., p. 34).

He aquí, la importancia que refleja la filosofía de la liberación latinoamericana:

(...) marca el giro innovador por el que la reflexión filosófica en América Latina, a nivel sistemático y explícito, entronca con la realidad social y la cultura del subcontinente, empezando así este discurso propio marcado por diferencias contextuales y culturales. La filosofía empieza de esta suerte a tener un rostro y una lengua latinoamericana. Pero justo en esa medida empieza también a distinguirse de otras formas de filosofía; y en especial, de la (dominante) forma europea. (Ídem).

Es así como el contexto y la cultura son la principal fuente de diálogo, porque las voces de allí emanadas es una comprensión e interpretación de ver el mundo desde lo propio y no desde una visión metafísica ajena: “en el diálogo intercultural filosó- 
fico las filosofías no hablan sólo sobre, sino ante todo con y desde su correspondiente diferencia histórica" (op. cit., p. 36). Importante resaltar la diferencia.

Desde esta perspectiva, hay un rompimiento entre filosofía europea y latinoamericana dado por un proceso de inculturación que consiste en: "liberar la filosofía para la polifonía cultural" (op. cit., p. 37). Y, así se establece una nueva relación entre ambos contextos filosóficos, que es "relación entre sujetos que se interpelan y que encaran en libertad [para] la tarea de la reciproca comunicación" (Ídem.). Porque ya el otro no es materia objeto de una racionalidad instrumental, "sino es un sujeto de un pensamiento propio en proceso" (ídem).

Ante tal reto, plantea el autor la necesidad de replantearse los presupuestos de "nuestra propia teoría del entender", que está acompañado de un desafío hermenéutico, es decir, de comprensión e interpretación desde lo propio. En primer lugar, una primera tarea y primordial es la trans-formación de esa racionalidad de comprensión del mundo y de la historia, donde la toma de consciencia de formar parte de ella es una necesidad y un compromiso que debe asumir el "otro" para ser protagonista de un dialogo.

Esta filosofía intercultural, partiendo de la filosofía de la liberación latinoamericana, como pensamiento propio debería ser la base de un programa de formación de nuestra racionalidad. Siguiendo con la problemática hermenéutica de esta nueva racionalidad, un segundo desafío, sería:

(...) no convertir nuestra propia manera de pensar en el lugar del encuentro del otro; es decir, no hacer de nuestro mundo categorial el centro desde el cual nosotros 'comprendemos' al otro, en el sentido de definirlo y determinarlo a la luz de nuestro horizonte de comprensión... (ídem).

Es importante resaltar este punto, porque si lo hacemos, comprender al otro que no somos nosotros, es decir, la modernidad desde nuestras construcciones categoriales caeríamos en la misma forma de actuar de la razón moderna. Por tanto, lo que se busca con este diálogo intercultural es "intentar ganar el acceso hacia el otro no desde nuestro propio modo de pensar, sino desde la situación histórica del encuentro con él, que es ante todo el momento donde su presencia patentiza la fuerza discursiva alternativa..." (op. cit., p. 41).

Este encuentro es una interpelación entre horizontes de comprensión donde se respete las posiciones originales. Por consiguiente:

El otro es entonces, principalmente allí donde nos sale al encuentro en la alteridad de una forma de vida o cultura, una perspectiva abre el todo (...) No obstante condición de esa posibilidad es justo la disposición a aceptarlo como (...) indefinible desde mi posición originaria, desde el que se levanta un nuevo horizonte de comprensión u orden del saber. (ídem). 
La interpelación con la alteridad del otro, reconociendo y respetando lo que se es, no definiendo desde nuestra construcción categorial.

Un tercer reto es:

(...) el replanteamiento propuesto de nuestra teoría del entender tendría que hacerse cargo de que el otro, precisamente por ser sujeto histórico de vida y de pensamiento, no es nunca constituible ni reconstruible desde la posición de otro sujeto. Frente al otro no cabe entonces la reconstrucción teórica desde mi forma de pensar, sino la reserva teórica del que se pone a escuchar el discurso de otra forma de pensar, y vislumbra ya en esa escucha el comienzo de la trans-formación recíproca. (op. cit., p. 42)

He aquí el movimiento fundamental de este diálogo intercultural, desmontar lo teórico de las unilateralidades con que se ha formado el pensamiento etnocéntrico, por "el diálogo intercultural de los modos de pensar vigente" (op. cit., p. 43). Desde esta perspectiva, la filosofía intercultural brinda un horizonte guía para establecer esos lineamientos aproximados de una "ética dialógica” latinoamericana.

\section{CONSIDERACIONES FINALES}

La reflexión realizada sobre una "ética dialógica" latinoamericana propuesta a partir de algunos matices filosóficos de pensadores latinoamericanos como Enrique Dussel y Raúl Fornet-Betancourt, permite establecer lineamientos importantes para la construcción aproximada de la propuesta teórica. En este sentido, se parte de la idea primordial de que el sujeto latinoamericano es habitante de un contexto específico, es un hombre situado. Lo que le da tal característica es la palabra, porque ella da existencia al sujeto al expresarse de él y necesaria para eso proceso dialógico de reconocimiento de sí mismo como ese Otro que es. Por consiguiente, el sujeto latinoamericano se sitúa en la universalización del pensamiento por la palabra.

El Otro, como rasgo constitutivo de su existir tiene la libertad creadora. Representa la potencialidad de autodeterminarse, un modo de ser propio, un modo de ser que no tiene que ser semejante a otras culturas, es decir, un rompimiento a los modelos o arquetipos establecidos, y esta libertad es lo que al Otro lo hace ser un sujeto que forma parte de la humanidad.

El pensamiento constitutivo de este pensar lo podemos ubicar en la filosofía de la liberación latinoamericana, punto de partida para una ética de la liberación donde el Otro oprimido es el origen de esta constitución teórica. Así, el reconocimiento del Otro como otro es el momento ético originario porque se le da el lugar al Otro, Otro libre, Otro como sujeto de nuevo derecho, en la nueva comunidad de comunicación dialógica. Resulta claro que el Otro forma parte de la existencia 
histórica mundial del cual ha sido invisibilizado, por los historiadores del etnocentrismo, obviando su constitución de sujeto y sólo tomándolos como objetos. Por tanto, la toma de conciencia del Otro, implica tener el saber de qué se es afectado, de ser un dominado dentro de los sistemas establecidos, como el pobre que no puede reproducir su vida en todos los contextos.

Es significativo acotar que el Otro es una realidad plena de sentido, de memoria, de cultura, de una comunidad, en palabras de Dussel "comunidad de las víctimas", un "nosotros-estamos-siendo" como una realidad resistente a los sistemas establecidos. Este Otro, tiene una razón ética originaria, que le permite establecer el reconocimiento del otro y proveer una acción comunicativa en el encuentro con el otro. A esta razón, la sustenta el principio de liberación que le permite descubrir el rostro encubierto que posee, y se reconocer como Otro en un proceso de liberación.

A partir de lo señalado, confluye la polifonía de voces, esa sintonía y armonía de las diversas voces por el continuo contraste con el Otro y el continuo aprender sus opiniones y experiencias. Un aprender, entonces, desde la propia tradición cultural, pero sabiéndola y viviéndola como tránsito y puente para la intercomunicación. He aquí, que lo propio es un camino que nos transporte hacía lo propio y hacia los demás, que son elementos constructivos de una universalización de comprensión e interpretación mutua.

Así, se establece que el contexto y la cultura es la principal fuente de diálogo porque las voces de allí surgidas es una comprensión e interpretación de ver el mundo desde lo propio y no desde una visión metafísica ajena. Por tanto, es necesario el desarrollo de una teoría propia del entender, para el establecimiento de una "ética dialógica" latinoamericana. En este sentido, la tarea primordial es la transformación de esa racionalidad de comprender el mundo y la historia, donde la toma de conciencia forma parte de ella, es una necesidad y un compromiso que debe asumir el Otro para ser protagonista de un diálogo. Y, la comprensión del otro se establece desde la posición del mundo de ambos dialogantes en igual de condiciones.

Por tanto, los posibles elementos constitutivos de esta "ética dialógica" latinoamericana, la encontramos en primer lugar, en el principio universal de "la vida del sujeto como criterio de verdad", un principio material que es válido para toda la humanidad. Un segundo elemento, es el "Otro" junto con la "palabra" y la "acción"; el "Otro" que existe porque tiene vida desde un punto de vista biológicocorporal, tiene la "palabra" para hacerse de su lugar en la historia universal de la humanidad como sujeto histórico en ese "encuentro" como "acción" que debe ser narrada para posicionarse en la existencia. Y, debe ser un encuentro histórico, que no parta de nuestro modo de pensar sino de la situación histórica entre la "comunidad de víctimas" con el etnocentrismo y configurar a partir de allí el diálogo intercultural necesario para el mundo. 


\section{BIBLIOGRAFÍA}

Contreras Natera, M.A. (2014). Otro modo del ser o más allá del euroccidentalismo. Caracas, Venezuela.

Díaz Novoa, G. (2000-2001). Enrique Dussel en la filosofía latinoamericana y frente a la filosofía eurocéntrica. Tesis Doctoral. Universidad de Valladolid, España. Disponible en: https://elartedepreguntar.files.wordpress.com/2009/12/diaz-novoa-enrique-dussel-en-lafilosofia-latinoamericana.pdf

Dussel, E. (1998a). Arquitectónica de la ética de la liberación. Capítulo de libro: La ética de la liberación: ante el desafio de Apel, Taylor y Vattimo con respuesta critica inédita de K.-O. Apel. Universidad Autónoma del Estado de México. México. Disponible en: http:// biblioteca.clacso.edu.ar/clacso/otros/20120507094311/3cap1.pdf

Dussel, E. (1998b). Ética de la Liberación en la Edad de la Globalización y de la Exclusión. Universidad Nacional Autónoma de México, México.

Dussel, E. (1996). Filosofía de la Liberación. Cuarta edición. Bogotá, Colombia: Editorial Nueva América

Fornet-Betancourt, R. (2001). Transformación intercultural de la filosofía. Bilbao, España: Editorial Desclée de Brouwer.

Gaos, J. (2008). Filosofía de la filosofía. México: Fondo de Cultura Económica.

Martín S., A. (2009). Introducción a la ética y a la crítica de la moral. Primera edición, tercera reimpresión. Caracas, Venezuela: Vadell Hermanos Editores.

Mignolo, W. (2007). La idea de América latina. La herida colonial y la opción decolonial. Primera edición. Editorial Gedisa. Barcelona, España.

Zea, L. (2010). La filosofía americana como filosofía no más. Primera edición, novena reimpresión. Siglo XXI editores: México. 